\title{
Coping With the Effects of Fear of Failure: A Preliminary Investigation of Young Elite Athletes
}

\author{
Sam S. Sagar \\ Leeds Metropolitan University \\ David Lavallee \\ Aberystwyth University \\ Christopher M. Spray \\ Loughborough University
}

\begin{abstract}
Coping with stress is an important element in effective functioning at the elite level in sports, and fear of failure (FF) is an example of a stressor that athletes experience. Three issues underpin the present preliminary study. First, the prevalence of problems attributed to FF in achievement settings. Second, sport is a popular and significant achievement domain for children and adolescents. Third, there is a lack of research on FF in sport among this population. Therefore, the objectives of the study were to examine the effects of FF on young athletes and to find out their coping responses to the effects of FF. Interviews were conducted individually with nine young elite athletes (5 males, 4 females; ages 14-17 years). It was inferred from the data that FF affected the athletes' well-being, interpersonal behavior, sport performance, and schoolwork. The athletes employed a combination of problem-focused, emotion-focused, and avoidance-focused coping strategies, with avoidance strategies being the most frequently reported.
\end{abstract}

Effective coping responses to fear of failure (FF), which is a source of stress and anxiety for athletes (Conroy, Willow, \& Metzler, 2002; Gould, Horn, \& Spreemann, 1983), are important at elite level sports. Coping with stress and the demands of sport is an essential element in effective functioning at the elite level where many potential sources of stress are involved (Gould, Eklund, \& Jackson, 1993; Scanlan, Stein, \& Ravizza, 1991). Sport presents many situations that athletes can perceive as threatening, challenging, or harmful (e.g., defeat, injuries, performance slumps, performing in a crucial competition). Athletes who do not posses effective coping skills to deal with such situations are likely to experience

Sam S. Sagar is with the Department of Psychology at Leeds Metropolitan University, UK; David Lavallee is with the Department of Sport and Exercise Science at Aberystwyth University, UK; and Christopher, M. Spray is with the School of Sport and Exercise Sciences at Loughborough University, UK. E-mail: S.Sagar@leedsmet.ac.uk. 
poor performance, negative affect, and may eventually drop out of sport (Madden, 1995). Therefore, elite athletes need to develop and use a variety of cognitive and behavioral coping skills to manage these demands (Crocker \& Graham, 1995). Failure to cope effectively has been described as a problem in elite performance (Crocker \& Isaak, 1997; Jackson, Mayocchi, \& Dover, 1998). Due to limited research on FF in the sport domain, however, we have little knowledge on how FF impacts elite athletes and how they respond to its effects.

Coping is a dynamic process that involves a person's constantly changing cognitive and behavioral efforts to manage (i.e., minimize, reduce, master, tolerate) external and internal demands that are appraised as stressful (Lazarus, 1999). Accordingly, there are individual differences in coping responses, as they are dependent on the individual's evaluation of his or her personal control and resources to reduce the stressor (Lazarus, 2000). Lazarus $(1999,2000)$ stated that coping is a process that involves psychological action tendencies and is a key variable in emotions (especially negative emotions that are based on harm and threat). Negative emotions follow appraisal of harm, loss, challenge, or threat to one's meaningful goal(s) and well-being and include anxiety, fear, and shame. A coping response follows emotions and takes the form of emotion-focused coping (EFC), problem-focused coping (PFC), and avoidance-focused coping (AFC) strategies that aim to control the stressor or the impact of the stressor. Emotion-focused coping strategies are often employed when one perceives that nothing can be done to modify the source of the stress and, as such, the individual aims to reduce the emotional distress (e.g., through reinterpretation, positive self-talk, social support). Problem-focused coping strategies are task-focused strategies that aim to reduce emotional distress by directing efforts to alter or manage the source of the distress. They include strategies such as making decisions, resolving conflicts, planning, gathering information, and acquiring resources (e.g., skills, tools) to help deal with the underlying problem (Folkman \& Moskowitz, 2000). Problemfocused coping has been found to be positively related to positive affect and wellbeing during stressful situations as it allows individuals to focus their attention and to assert control over the stressor (Carver \& Scheier, 1998). Avoidancefocused coping refers to attempts to neutralize distressing emotions by avoiding dealing with the problem, thereby reducing tension through cognitive and behavioral disengagement (escapist) strategies (e.g., sleep, daydreaming, distraction; Carver, Scheier, \& Weintraub, 1989). While AFC does in fact reduce distressing emotions in the short-term, such efforts are ineffective for managing long-term threats and are associated with negative emotional and motivational outcomes (Carver et al., 1989; Parker \& Endler, 1996).

Coping and emotion regulation are constructs that overlap, but they differ in that coping has a predominant focus on negative affect reduction over much longer periods of time than does emotion regulation (Gross \& Thompson, 2007). Gross (e.g., Gross, 2001, 2002; Gross \& Thompson, 2007) defined emotion regulation as the processes by which individuals influence which emotions they experience, when they experience them, and how they express them. Thus, it is a process that involves changes in behavioral, experiential, and physiological responses. Gross's model of emotion regulation suggests two self-regulatory strategies that aim to modulate negative emotional responses: reappraisal and suppression. Reappraisal, which occurs early in the emotion-generative process, involves changing how one 
thinks about the situation to change its emotional significance. Hence, one cognitively reevaluates potentially negative emotion-inducing situations in an effort to alter the meaning of the situation. Suppression, which occurs later in the emotiongenerative process, involves actively inhibiting the outward signs of emotion that are generated as the emotion unfolds. Thus, it aims to inhibit ongoing emotional experience and expression (i.e., emotions, behaviors, cognitions) after the emotions begins to occur. Reappraisal is said to be more effective than suppression, and results in healthier outcomes (Gross, 2001, 2002; Gross \& Thompson, 2007).

\section{Fear}

Fear is a subjective emotion that triggers physiological changes (e.g., increased heart rate, muscle tension) and that has antecedents in the environment, leading to certain causal consequences in behavior (Gray, 1987). Fear is an emotional reaction to a perceived threat that one seeks to escape or avoid. An association between a specific stimulus and threat triggers a fear response, and avoidance behaviors often ensue. The individual engages in the avoidance behaviors out of a belief that such behaviors will prevent the unpleasant outcome that is feared (Barlow, 2002; Field \& Lawson, 2003; Gray, 1987). Avoidance behavior (i.e., emotional and cognitive avoidance) has been referred to as experiential avoidance, whereby individuals seek to avoid, escape, or modify the internal experience (Hayes, Strosahl, Wilson, Bissett, \& Pistorello, 2004; Hayes, Wilson, Gifford, Follette, \& Strosahl, 1996). Experiential avoidance is viewed as a pathological process and is defined as "the phenomenon that occurs when a person is unwilling to remain in contact with particular private experiences (e.g., bodily sensations, emotions, thoughts, memories, behavioral predispositions) and takes steps to alter the form or frequency of these events and the contexts that occasion them" (Hayes et al., 1996, p. 1155). Accordingly, it is an attempt to avoid or control internal experiences (cognitive, emotional, and physiological). At the heart of psychopathology is the avoidance of painful feelings or fear of unwanted emotions and, as such, experiential avoidance has been recognized as a problematic aspect of human functioning (Hayes et al., 2004).

Patterns of fear have been documented from early childhood into adulthood (e.g., Field \& Lawson, 2003; Lawson, Banerjee, \& Field, 2007; Morris \& Kratochwill, 1998). Fears are generally accepted as normative during childhood and are considered as an adaptive emotional reaction to threat (real or imagined). Fears are adaptive aspect of development that warn one of dangers and motivate escape or avoidance behavior (Barlow, 2002; Field \& Lawson, 2003; Gerull \& Rapee, 2002; Gullone, 1999). If fears become excessive, intense, and persistent over time, they can lead children and adolescents to experience significant distress and discomfort and can act as barriers to academic and social development (Field \& Lawson, 2003; Gullone, 1999). Extreme fears (i.e., disproportionate, irrational, involuntary fear reaction) are categorized as phobias and can severely impact an individual's functioning in a variety of life domains (Field \& Lawson, 2003; King, Gullone, \& Ollendick, 1998). On the other hand, normative and nonpathological fears, which are typical among children and adolescents, have a much less severe impact on individuals; however, they can influence one's comfort level and 
reactions to people and situations in the environments (Schaefer, Watkins, \& Burnham, 2003). Although some fears are innate (e.g., loud noises, loss of support), others require cognitive maturation to develop (e.g., fear of criticism, school related fears; Gullone, 1999). Three main fears have been described among children and adolescents: performance anxiety, social anxiety, and school phobia (King et al., 1998).

\section{Conceptualization of Fear of Failure}

Early achievement motivation theories (e.g., Atkinson, 1964; McClelland, Atkinson, Clark, \& Lowell, 1958) defined FF as the motive to avoid failure because one feels shame and humiliation upon failure. Thereby, FF has been conceptualized as unidimensional and as a personality trait (in terms of a capacity to anticipate negative affect in achievement or evaluative situations). They proposed two achievement orientations: one that orients individuals to seek the avoidance of failure in achievement settings and another that orients individuals toward the achievement of success. As such, FF and need for achievement were conceptualized as separate motive dispositions. The motive to avoid failure typically develops between the ages of 5-9 years (McClelland, 1958). In contrast to these early theories, contemporary theories also view FF as a personality trait but conceptualize it as a hierarchical and multidimensional construct that motivates individuals to avoid failure because they fear its various aversive consequences (e.g., Conroy, Poczwardowski, \& Henschen, 2001; Conroy, Willow, \& Metzler, 2002).

Researchers have proposed that people fear the consequences of failure if they perceive them to be aversive (e.g., Birney, Burdick, \& Teevan, 1969; Conroy et al., 2001; Conroy et al., 2002), and the anticipation of threatening outcomes elicits fear and anxiety (Lazarus, 1999, 2000). Threat is the condition that exists when people are confronted with a stimulus that they believe will endanger important values and goals (Lazarus, 1999, 2000). Thus, if athletes perceive that they will not meet the demands of sport (e.g., winning, performing well), they are likely to feel that their goals are threatened. Perceiving that failure to meet such demands will endanger their chances of achieving their desired goals and aspirations, it is likely that they will perceive failure as a threat and fear such failure. As such, a conceptualization that guided the current study is that fear of the aversive consequences of failure and $\mathrm{FF}$ are equivalent constructs.

Cognitive-motivational-relational theory of emotion (Lazarus, 1991, 1999) posits that once individuals perceive relational changes (threat) indicating failure, they must appraise (primary appraisal process) how those changes affect their ability to accomplish their goals. In this appraisal, individuals determine whether their goals are impacted by the perceived threat, which goals will be impacted, and how important achieving those goals is to them. From this perspective, FF in achievement (or evaluative) situations involves appraising threat to achieve personally meaningful goal(s) when one fails in the performance. Such appraisal activates cognitive beliefs (schemas) associated with the aversive consequences of failing (or of not succeeding) and leads to experiencing fear (Lazarus, 1991, 1999). Five beliefs about the consequences of failure that are associated with threat appraisal and that form the basis for five fears of failure have been identified by Conroy and colleagues (Conroy et al., 2002). These are fear of experiencing 
shame and embarrassment, fear of devaluing one's self-estimate, fear of important others losing interest, fear of having an uncertain future, and fear of upsetting significant others. As stated, many individuals learn to associate failure with aversive consequences and therefore experience fear and apprehension in evaluative situations (Conroy \& Elliot, 2004). Thus, FF represents a learned dispositional tendency. The strength of belief about the likelihood that these aversive consequences will occur after failure differs between individuals and, hence, the level of fear that individuals experience also differs. Accordingly, FF can be viewed as a learned personality trait or a schema (Young, Klosko, \& Weishaar, 2003) that orients individuals to experience fear and anxiety in achievement contexts.

High FF has been associated with a prevalence of negative psychological and physical effects (e.g., eating disorders, anxiety, worry, shame, depression) on individuals frequently involved in achievement tasks (see Conroy, 2001 for a review). In education-related research, FF was reported to be prominent in both sexes and across levels of actual and perceived ability (Covington, 1992; Elliot \& Church, 1997). Fear of failure underpins the adoption of performance-avoidance goals, which can elicit anxiety, lead to debilitate performance, and cause individuals to lose interest in the activity and eventually to drop out (e.g., Elliot \& Harackiewicz, 1996; Elliot \& McGregor, 2001). Accordingly, FF has important implications for athletes.

In sport-related research, fears of failure and disapproval (or of negative social evaluation) have been reported to be the most prevalent sources of worry and maladaptive stress among athletes because for many athletes, athletic success is a major source of recognition and self-esteem (Martens, Burton, Vealey, Bump, \& Smith, 1990; Smith, 1989), and self-worth is often linked to one's accomplishments (Covington, 1992). Research on youth participating in sport has shown that both worries about process (e.g., not playing well, making mistakes) and outcome (e.g., losing, criticism from parents and coaches) were correlated with FF. For example, young elite athletes' worries were related to fear of failure, fear of negative evaluation, feelings of inadequacy, and external control or guilt (Gould, Horn, \& Spreemann, 1983). Junior elite wrestlers (aged 13-19 years: Gould et al., 1983; aged 9-14 years: Scanlan \& Lewthwaite, 1984) and runners (aged 9-15 years: Feltz \& Albrecht, 1986) reported worrying most frequently about making mistakes, not performing to their ability, not improving on their performance, not participating in championship events, and losing. These studies concluded that failure and negative social evaluation are predominant sources of worry among many young athletes.

Interestingly, it has been suggested that FF actually has no direct effect on sport performance but primarily has an indirect influence on cognitive performance (attention) via worry (Hosek \& Man, 1989). Therefore, the attentional shift that accompanies worry can directly impact performance success.

\section{Purpose and Rationale}

To date, the concept of FF has been studied primarily in academic settings (e.g., Elliot \& Harackiewicz, 1996; Elliot \& Sheldon, 1997; Martin \& Marsh, 2003) and has been greatly neglected in sport despite the reported prevalence of problems attributed to high FF in achievement settings (e.g., Conroy, 2001; Elliot \& Shel- 
don, 1997) and despite sport being a popular and significant achievement domain for individuals of all ages (Treasure, 2001). Consequently, further research into FF in sport, and among youth in particular, is greatly needed. Therefore, the focus of the present preliminary study was to investigate FF among young athletes, specifically among those performing at elite levels of competition (national and international) in the public arena, whose performances are regularly evaluated by selectors (or judges) and the public, and where failure can have adverse consequences for the athletes. Elite level athletes invest substantial time in their sport and the results of their performances can have potent consequences on their lives and future sporting careers (Conroy et al., 2001).

The athletes participating in the current study were part of a larger program of research that examined their perceptions of the consequences of failure (Sagar, 2007). The objectives of the current study were twofold. First, we examined the effects that FF had on the athletes. Second, we examined how the athletes coped with the effects that FF induced before competitions. Due to a small number of young elite athletes participating in the current study, a qualitative methodology was deemed suitable (Folkman \& Moskowitz, 2000).

\section{Method}

\section{Participants}

Eleven British male and female elite athletes ages 14-17 years volunteered to participate in the study. Athletes were drawn from a specialist sports school in the East Midlands of England. Two of these athletes were interviewed for a pilot study and subsequently were excluded from the main study. The remaining nine athletes ( 5 males, 4 females) were involved in a range of sports, including tennis ( $n=3$ males), kickboxing ( $n=1$ male), triathlon $(n=1$ female), basketball $(n=1$ male), field hockey ( $n=1$ female), and football (soccer; $n=2$ females). At the time of the interviews, all of the athletes were performing at the national level and each reported 1.5-5 years of competitive experience at the international level.

\section{Procedures}

The procedure involved the following stages:

Stage 1: Seeking Consent. Access to the athletes was obtained through a specialist sports school in the United Kingdom. Letters and consent forms were sent to the athletes and their parents (or carers in the cases of athletes who lived at the school and were away from home) via the school's coordinator. The letters explained the requirements, aims, and procedures of the study and assured the volunteers complete anonymity. The consent forms required the signatures of both the athletes and their parents (or guardians) before participation in the study.

Stage 2: Initial Meeting. After receiving the consent forms from the athletes, an initial 15-minute preinterview meeting was arranged (via the school coordinator) with each athlete (individually). The aims of these initial meetings were to meet the athletes for the first time and to build rapport (Arskey \& Knight, 1999). They also served to explain the general aim of the study (i.e., to learn about young ath- 
letes' experiences of failure in sport), to answer the athletes' questions regarding the study, and to discuss any concerns that they might have about participating in the study. We also sought to ensure that they agreed to participate in the study of their own free will and to arrange a convenient interview time for both parties.

Stage 3: The Interview. An interview was conducted with each athlete individually at the school in a quiet room where only the athlete and the primary researcher were present. Interviews lasted between 55 and 90 minutes and were audio taped.

\section{Pilot Interviews}

Two pilot interviews were conducted (and audio taped) individually with two female runners (both 16 years of age) before interviews to test and refine the interview guide. These pilot interviews tested the order in which the interview questions were asked and the links between them (allowing for flow and orderly sequence), to test for appropriateness and comprehension of questions and terms, and to make amendments accordingly. Based on the athletes' feedback after the pilot interviews, the researchers' evaluations of these interviews, and the critique from a colleague who specializes in qualitative research and interviewing techniques, modifications were made to simplify the wording of the questions and their order in the interview guide. The final guide was used to interview the nine athletes who participated in the current study.

\section{Interview Design and Structure}

A semistructured interview was conducted with each athlete individually to allow them to relate to their own experiences in a free and open manner and to disclose more information than perhaps they would disclose in a focus group interview. A predesigned interview guide was used as a flexible framework for the interview and was based on key questions most relevant to the study (Arskey \& Knight, 1999). It contained open-ended questions, elaboration, and clarification probes to be used during the interview to clarify, expand, and deepen the athletes' responses. Although all the athletes were asked the same questions and in the same way, the order of topics and the order of questioning were free to vary within the natural flow of the conversation and related issues that were thought to be important by the athletes were allowed to surface.

The interview guide was divided into four sections, along with pre- and postinterview sections. The preinterview section aimed to establish rapport and orient the athletes to the interview process, to reiterate to the athletes the aims of the study, the reasons for audio taping the interview and the use of data, to explain the structure of the interview, to assure them confidentiality, to encourage them to give honest and accurate responses to the questions asked, and to remind them that they can decline answering any questions and that they could terminate the interview at any point.

The first section of the interview was an introductory section that began with general background questions about the athletes' sporting career (e.g., "Tell me how you got into your sport and at what age," "When did you begin playing at elite level?" "Tell me who inspired, supported and encouraged you during your 
career"), demands of the sport, and how they managed to balance the demands of their sport with those of the school. This section aimed to build further rapport and trust with the athletes so that they would not feel threatened to disclose what may be private information and to ease them into the interview (Arskey \& Knight, 1999).

The second section of the interview aimed to ascertain the athletes' perceptions of failure in sport. They were asked, "How do you define failure in sport?" and "What does failure in sport mean to you?"

The third section aimed to establish past effects of FF on the athletes and their coping responses. Questions were retrospective in nature. The athletes were asked to describe their emotions, cognitions, behaviors, and coping responses to FF before a competition that they considered important and that took place in the last month (e.g., "Tell me how you felt before going to this competition," "Tell me what thoughts you had before this competition about losing/getting beaten/not winning," "Tell me how these thoughts affected you," "Tell me what you did or said to yourself to help you deal with and get over these thoughts"). The athletes described important competitions as selection events, international events, and important games in the season. The use of the terms "losing/getting beaten/not winning" in the questions echoed the specific athlete's perception of failure in sport that had been established earlier in the second section of the interview.

The fourth section aimed to ascertain current experiences of FF, their impact on the athletes, and the athletes' coping responses. Questions were prospective in nature. The athletes were asked about (a) competitions that were approaching in the coming month that they considered important and in which they were expected to compete (e.g., "What is your next important competition? Where? When?" "Tell me what you know about your opponent," "Describe how you are preparing for it"); (b) their fears of failing in this competition (e.g., "Tell me how you feel about going to this competition," "Tell me what thoughts you have about losing/ getting beaten/not winning in this competition"); (c) how these fears were currently impacting their behavior (e.g., "Tell me how these thoughts are affecting you"); and (d) how they were coping with them (e.g., "Tell me what you do or say to yourself to help you deal with these thoughts").

At the end of each section, the athletes were asked whether there was anything else they could add concerning what had been discussed and whether they were comfortable to carry on with the interview. Finally, the postinterview debriefing offered both parties an opportunity to clarify and refine aspects of the interview and to unwind the interview by changing the focus to less personally directed issues. Furthermore, it offered the athletes the opportunity to reflect on the interview process and experience, to talk about some of the issues that were raised in the interview, and to "let go" of any emotions that an interview can evoke (King, 1996). All interviews were conducted by the first author, who is trained in qualitative research methods, is experienced in conducting interviews, and has training in counseling skills.

\section{Data Analysis}

All interviews (a total of 13 hours) were transcribed verbatim and were inductively analyzed using the principles of thematic analysis (Smith, 1995) and some principles of grounded theory analysis (e.g., coding, constant comparison, memo 
writing; Strauss \& Corbin, 1990) to identify common themes and categories that represented the effects of and coping responses to FF. A computer software package, QSR NUD*IST N6 (2002), was used to facilitate data analysis (e.g., organizing data, coding, categorizing).

The basic units of analysis were the raw-data quotes that were extracted from their interview transcripts. These were quotes that captured a distinct concept and were defined as "segment of text that is comprehensible by itself and contains one idea, episode or piece of information" (Tesch, 1990, p. 116). Through the process of inductive analysis, the quotes were organized into a hierarchical structure of themes and categories. The inductive process, which moves through a number of stages, reveals essential themes (by determining which parts of the descriptions are essential and which are not) and determines the relation between the themes and how they reflect the phenomena studied, therefore allowing the meaning of social phenomena to be explained (Sullivan, 2003). The researchers coded the data and conducted code checks to assure coding reliability (interrater reliability) and to minimize interpretive bias (Patton, 2002). Following several discussions between the researchers and after reaching a mutual consensus, the final higherorder themes and categories were established. Lower-order themes were assigned names that were as close as possible to the athletes' words and higher-order themes and categories were assigned names using the language of social science.

\section{Trustworthiness of Data}

A collaborative approach was taken in the process of data analysis to enhance the trustworthiness and credibility of data analysis and to reduce interpretive bias (Patton, 2002). Following a collaborative effort of the researchers in the process of interpretation and reconstructing participants' meanings (e.g., coding the data, establishing themes and categories), the data were verified and contextualized.

Credibility of the analysis process was also established through an audit trail (e.g., journals, memos), which is a record of the development of the analysis process. This allowed us to verify rigor and minimize interpretive bias (Patton, 2002). Team members acted as peer debriefers by going through the audit trail and raising questions of bias when necessary. Furthermore, QSR NUD*IST N6 (2002) allowed for maximizing the transparency of the analytical process (Bringer, Johnson, \& Brackenridge, 2004).

\section{Results}

All of the athletes perceived failure in sport as outcome oriented, such as "losing," "not winning," and "getting beaten." Some also perceived failure as performance oriented, such as "not doing your best" and "not performing well" (A2, 3, 4, 5, 7), "not meeting the goals and expectations" (A1, 2, 5, 8, 9), and "having people view me as a failure" (A5). The most common fears expressed by the athletes were fears of losing/not winning/getting beaten $(n=9)$. For example, "I'm scared of losing and I get nervous" (A2), "(before a big game) I feel 'Oh God I don't want to play this game I might lose", (A5), and "When you play a team that you are really suppose to beat ... then there's a bit of fear that you might just lose, it could happen, you may fail" (A4). 
Six athletes revealed that the conditions under which they feared failure most were before selections events, crucial games in the season, and international tournaments. This was captured eloquently in athlete 5's statement, "The bigger the tournament, the bigger the game, the bigger the event, it just makes your fear of failure grow and grow and grow."

The main results of the current study focused on the effects of FF on the athletes and on their coping responses to the effects of FF. Each will be presented separately below.

\section{Effects of FF}

It was inferred from the results that FF affected the athletes in four ways: their well-being, their interpersonal behavior, their sport performance, and their schoolwork (see Appendix 1). Each one of these effects will be presented separately below.

Effects of FF on Well-Being. Fear of failure appeared to increase the athletes' ( $n$ $=8$ ) negative cognition and emotions in the period before competition, impacting their well-being, affect, and self-perception and motivation. The effects on their emotional state encompassed (a) feeling anxious, $n=5$, e.g., "It [FF] makes me a bit jittery in the game" (Athlete 4; A4); "I feared failure a couple of days of the build up . . . I felt nervous . . . I wouldn't say that I slept very well” (A5); “A day probably before the match ... I just become a lot more nervous and anxious about the match and about how well I want to do and people try to calm me down but I still stay nervous" (A9); (b) feeling worried, $n=5$, e.g., "I worry about it [the race] a lot ... probably about two hours before or the night before" (A1); "I worry about failure about a week before the tournament" (A3); (c) feeling stressed, $n=2$, "I tense up and get stressed" (A2); "It's [FF] stressful" (A5); (d) feeling scared, $n=$ 1 , "It [FF] breaks down your confidence and then you don't do as well because you're scared" (A2); and (e) feeling upset, $n=1$, "It takes me a long time to sort myself out ... I'll be upset for quite a while" (A2).

The effects on self-perception and motivation encompassed (a) losing selfconfidence, $n=3$, e.g., "FF just eats you away really, if you're constantly thinking you're going to fail then it makes you less confident and not feel so good about yourself and your capabilities . . . you just feel like maybe you're not capable of doing it, you just have doubts in your mind about being able to take on the challenge" (A5); (b) losing motivation, $n=1$, "It [FF] affects your motivation. It can make me feel 'Oh God I don't want to play this game I might lose'. . . It just makes you feel before a big game like we're not capable of taking this team on and you're just not motivated to go do it" (A5); and (c) having negative outlook, $n=2$, "I become very negative toward myself, it's always yourself" (A2); "It [FF] just makes you negative about things and you're just not feeling positive about things. ... You're thinking 'I'm not very good, I'm not playing well at the moment' . . . and you're thinking you're going to fail"' (A4).

Effects of FF on Interpersonal Behavior. Fear of failure also seemed to affect the athletes' $(n=4)$ interpersonal behavior, specifically affecting their social interactions for a brief period. The athletes reported (a) becoming irritable, less sociable, and less tolerant of the people around them, e.g., "You're not very nice to 
people, you just don't want people to be around and bugging you, you are just less capable of dealing with the world around you" (A5); "I get a little bit snappy and a bit nasty to people" (A9); and (b) communicating less with them, e.g., "I end up going quiet on everybody" (A3); "I become a bit quieter around people" (A8, 6); "I become quiet and don't talk" (A7).

Effects of FF on Sport Performance. It was also inferred from the data that FF adversely affected the athletes' $(n=3)$ sport performances. They stated, for example, "You don't take risks in the match" (A6), and "You play more cautiously. . . . You don't do what you normally do 'cuz you're afraid" (A4). The effect of FF on sporting performance is also illustrated in athlete 2's statement, "My biggest fear is that I will disappoint my mom . . . . I never want to let my mom down or my coach." She stated that due to her inability to cope effectively with her fears of failure, "I just couldn't handle the stress before [competitions] of 'This is important (competition) you can't mess up,'” she had dropped out of high level swimming and later out of high level tennis:

I did good times in training, but in competitions I swam slower, so FF affects you and your performance. ... With tennis it $[\mathrm{FF}]$ made my playing go down, my confidence went down, and I would play a game terribly because I just wouldn't hit the ball. . . . I was too scared and I had no confidence and I'd be cross with myself for not having the confidence to hit the ball. I'll go week after week to play a match and not be happy with it and at the end of the day it just made me depressed [sigh] (A2).

Effects of FF on Schoolwork. Fear of failure also appeared to affect a couple of the athletes' $(n=2)$ schoolwork, causing them to neglect it. They explained, "It $[\mathrm{FF}]$ affected my schoolwork because I wasn't concentrating enough on schoolwork and other things" (A5), and "I'd be just thinking about the game instead of thinking about my schoolwork or what I did last night, or something" (A8).

\section{Coping Responses to Effects of Fear of Failure}

Coping responses to the effects of FF were divided into three categories: avoidance-focused coping strategies (which were grouped into either cognitive or behavioral strategies), emotion-focused coping strategies, and problem-focused coping strategies (see Appendix 2). Each is presented separately below.

Avoidance-Focused Coping Strategies. Cognitive avoidance-focused coping strategies were described by all of the athletes interviewed $(n=9)$. Two higherorder themes were identified in this group: (a) mental disengagement $(n=9)$ and (b) try not to let FF affect me $(n=2)$. Mental disengagement consisted of one subtheme: pushing negative thoughts of failure away. It was described by the athletes $(n=9)$ as (a) pushing thoughts of failure away and keeping a positive mind, e.g., "You have that little worry but you try to put it to the back of your mind .... I try not to think about failure and just try to think about trying to do my best" (A8); "I try to think more positively than negatively like 'Oh what if I don't make it"' (A2); (b) pushing thoughts of failure away because thinking about failure leads to failure, e.g., "You push it (thoughts of failure) 'cuz if you think you're going to fail you're already one down on yourself, you already like lost before you 
get there" (A1); "I try not to think of failure "cuz I feel that I'm likely to end up failing" (A3); "Thinking of yourself as being a failure contributes to your failure" (A5); (c) try not to think about failure, e.g., "I know I can fail but I try not to think about it" (A6); (d) not think about failure, e.g., "I just didn't think of the possibility of failing so therefore I just gone on the field and played" (A2); (e) not think about the consequences of failure, e.g., "I try not think about the outcome"(A8); "I don't think of the consequences .... I just think I got to prove that I can do it" (A1); (f) thought control, e.g., "You just put the thought aside and it sorts itself out, you just relax about it" (A5); "You just not let the thoughts [of failure] come to your head because it's always going to be there but you can't let it come" (A6); and (g) think about other things, e.g., "I concentrate on the good games that I've played and things like that" (A8); "I try not to think about it [failure] and try to concentrate on other things that are happening. ... When they [thoughts of failure] come back I just try to forget about them even more" (A9).

Try not to let FF affect me was the second higher-order theme of cognitive avoidance-focused coping strategies and was described by two athletes as follows: "I try not to let it [FF] affect me, I don't know how [laugh]" (A1), and "I did think about failure before [the match] but I didn't let it affect me too much when I was playing, I just thought ' $I$ ' $m$ in a hockey match so just let me play' ... . You understand it (FF) and know that it's there but you don't let it affect you, so it works ... you learn to cope with it" (A2).

Behavioral avoidance-focused coping strategies were described by seven athletes. Four higher-order themes were identified in this group: (a) become quiet and seek isolation $(n=4)$, e.g., "I end up going quiet on everybody and try to stay focused instead of talking about different things.... I just keep myself to myself" (A3); "You become a bit quieter and go to a quiet place and think about it" (A6); "I feel nervous and act different, like I become quiet and don't talk" (A7); (b) not talk about FF $(n=2)$, e.g., "I wouldn't tell my coaches about it [FF] . . 'cuz they might think I can't cope with things . . . and I'm not going to be a strong enough performer" (A5); "We [players and academy coaches] don't talk about failure 'cuz you don't want it to be part of your life" (A7); (c) humor $(n=2)$, e.g., "You get more nervous when they're [team managers] watching the race ... I just stick my tongue out at them and laugh" (A1); "You try to joke" (A2); and (d) chill out $(n=1)$, "I chill out, like take a bath, read, not think about it [failure], go out, put things out of your mind, not focus on it. It helps me" (A5).

\section{Emotion-Focused Coping Strategies}

Emotion-focused coping strategies were described by all participating athletes $(n$ =9). This category was comprised four higher-order themes: positive self-talk, positive reinterpretation, lowering goals, and seeking emotional social support.

Positive Self-Talk. Positive self-talk $(n=5)$ was related to encouraging motivational statements and consisted of three lower-order themes: (a) positive self-talk, e.g., "you tell yourself just go there and give it your best" (A6); "I reassure myself how good I am ... It's like the opposite to fear" (A4); (b) self-affirmation, e.g., "I focus on 'I can do it, I've got to show them"' (A1); "I say to myself 'You can win 
this match", (A7); and (c) self-pep talk, e.g., "You'll be thinking 'Maybe I can't do it' and then you think 'No c'mon, prove to yourself that you can do it, that you're suppose to and that you're meant to be here' . . I think ' $C$ 'mon [own name] be strong!"' (A8).

Positive Reinterpretation. Positive reinterpretation $(n=7)$ was a coping strategy related to reframing perceptions. It consisted of four lower-order themes: perceiving FF as facilitative $(n=4)$, adopting a realistic view about failure $(n=7)$, accepting FF $(n=2)$, and turning to religion $(n=1)$. Each lower-order theme is described below.

Perceiving FF as facilitative consisted of three subthemes: (a) perceiving FF as a positive, e.g., "Worrying about failure is a good thing 'cuz it gives me an advantage in the game 'cuz I'm thinking about my game. . . . If you don't have worries then you're not going to be successful 'cuz you're not going to play to your best. The more you worry the more it will make you do better" (A8); (b) turning FF into a motivational source, e.g., "There's a bit of fear that you may fail . . . but it also motivates you" (A4); "It's the FF that keeps you going . . . that's what pushes you" (A8); and (c) believing that anything after failure is positive, e.g., "I just think that anything that happens after failure is positive . . . it can't get any worse, can it? [laugh]. So everything can be a plus after that" (A1).

Adopting a realistic view about failure consisted of four subthemes: (a) failure is just having a bad day, e.g., "Everyone has bad days . . . I will have just had a bad day and a bad race" (A1); (b) hope: "I'm not worried about failure 'cuz it happens, you just have to hope that it doesn't happen to you" (A1); (c) there is another chance in the future, "I don't worry 'cuz if I don't do well I've got another chance some day . . . if I don't get selected it's just unlucky . . . my time will come" (A8); and (d) failure is part of life and sport, e.g., "Failing is part of sport" (A3); I don't like failing but everyone has to fail, its part of life and the way things happen" (A4).

Accepting FF refers to accepting FF as part of sport and learning to deal with it. For example, "You can't think 'Oh there is lots of pressure on me to win' and collapse ... . You got a job and certain tasks to complete. Yes it's stressful . . . but if you get stressed about it you're not going to get it done" (A1), and "You can let the FF affect you or you can accept what it means and learn to live with it, and if it [failure] happens it happens, but it doesn't mean that it's your life, and you move on. . . . I think I just learned to deal with the pressure of 'This is an important thing you must play well,' and I learned to enjoy it more than getting worried about it ... . I think you might understand it [FF] and know that it's still there but you don't let it affect you" (A2).

Turning to religion was a strategy that only athlete 2 (who came from a religious family background) employed to cope with her FF. She stated:

I'll be upset for quite a long while and then I'll think "Sort yourself out!" . . The only thing that ever helped me to sort myself out ... was turning to God and trusting in Him. . . . When I'm scared of failing I just think, "Try your best and what happens is part of God's plan," and with this line of thought it just gets me through. 


\section{Problem-Focused Coping Strategies}

Problem-focused coping strategies were described by seven athletes. This category consisted of two higher-order themes: increasing effort to prevent failure, and confronting your fears.

Increasing Effort to Prevent Failure. Increasing effort in an attempt to prevent failure $(n=6)$ consisted of four lower-order themes: (a) increased training, e.g., "I got over FF by telling myself to do more training and then I'll be able to become better. . . . Sometimes I behaved strange like I would end up doing more training than I should do, so I'm pushing myself just because I feel like I could fail"' (A3); "When you have this fear you just want to be even better . . . you train harder. . . . You don't want to fail so you increase your training" (A6); (b) preparation is more exact, e.g., "It $[\mathrm{FF}]$ makes you think harder about how you're going to play. Preparation will be more exact. . . . I'd make sure that I stretched properly and eaten at the right time. . . . I'd make more effort. . . . I'll try hard. . . . I just put that extra" (A4); (c) concentrate harder, e.g., "You concentrate harder 'cuz if there's a chance of you failing you have to try and do things right and make sure that it doesn't happen. So FF makes you want to be more thorough in your actions in the game and do better to prevent failure" (A4); "FF makes me make sure more that I don't do daft things in the game, I'll make sure everything is more precise. I try and play better. . . . I concentrate harder . . . you'd be a lot more conscious in what you doing" (A9); and (d) learn about the opponent, e.g., "You're never confident at the first race of the season, it's the nastiest. . . . I like to find out before [the race] what people [opponents] have done and where they've been training . . . just in case they beat me" (A1).

Two athletes perceived their increased effort as increased motivation, stating, "FF makes you more motivated . . . you don't want it to happen but you know it can, so you do more to try and prevent it. So you put more effort into it" (A4), and "The nice thing about fearing failure is that it keeps me going and training and trying. Fear of failure motivates me to carry on trying 'cuz you don't want to fail [laugh]" (A2).

Confronting Your Fears. Confronting fears $(n=4)$ relates to challenging the fears of failure, e.g., "If FF is bothering you then if you deal with things head on, like confronting your fear is a better way" (A5); "You can't sort of turn away, run away from your fears, you have to face them" (A9) and to disregarding them and going ahead with the performance, e.g., "You do fear failure but then you just have to do it, to play the next time you go on the tennis court and play a match" (A6); "Even if I feel fear I'd still play and do my best, and I'd try and I just wouldn't not play" (A4); "I just think 'Just get it [the match] over with and see whatever happens"" (A5).

\section{Discussion}

The aims of this preliminary study were to examine the effects that FF had on young elite athletes and to find out how they coped with the effects that FF induced before competition. The findings represent one of the first attempts to document the effects of FF and the coping behaviors of young elite athletes. It was inferred 
from the data that FF increased the athletes' negative cognitions and concerns about failure for a short period of time. This subsequently led the athletes to experience a short-term increase in negative emotions (anxiety) and reduced self-perception and motivation. Perceiving threat elicits fear and anxiety, which are anticipatory emotions, as they are responses to possible future harm (Barlow, 2000; Lazarus 1991, 1999). Fear of failure seemed to lower the self-confidence of some athletes, making them adopt a negative outlook and reducing their motivation to perform, as they feared the possibility of losing and the associated consequences. As fearing failure can diminish individuals' perceptions of competence of involvement in the task, it can lead to avoidance behaviors aimed at escaping from the challenging tasks (Reeve, 2001). Avoidance behavior (i.e., emotional and cognitive avoidance) has been referred to as experiential avoidance, whereby individuals seek to avoid, escape, or modify the internal experience (e.g., bodily sensations, emotions, cognitions; Hayes et al., 1996, 2004). The avoidance of painful feelings or fear of unwanted emotions is at the core of experiential avoidance, which has been recognized as a problematic aspect of human functioning (Hayes et al., 2004). Achievement motivation theorists (e.g., Birney et al., 1969; Elliot \& Sheldon, 1997) advocated that FF motivates individuals to avoid engaging in achievement situations because they seek to avoid the consequences or experiences of failure. The tendency to avoid failure motivates them to defend against the loss of self-esteem, the loss of social respect, and feelings of embarrassment.

The present findings also indicated that FF increased the athletes' negative affect and cognitions, triggering physiological responses (i.e., tense). Most of the athletes reported that FF made them feel anxious, worried, stressed, scared, upset, and tense. Achievement situations typically challenge individuals' personal competence and, therefore, can evoke varying negative emotional reactions (Reeve, 2001). According to Gross and colleagues (e.g., Gross, 2002; Gross \& Thompson, 2007), emotions arise when something important and meaningful (i.e., a goal that is enduring, such as staying alive or a transient goal, such as winning a game) to the individual is at stake. Sometimes emotions (e.g., fear) can be triggered automatically while other times they can rise after considerable meaning analysis. Emotions coordinate sets of behavioral, experiential, and physiological responses that together influence how one responds to a perceived threat or challenge (Barlow, 2000; Gross \& Thompson, 2007). Lazarus (1999, 2000) also posited that emotions will occur when a person appraises encounters with the environment as having either a positive or negative impact for well-being in terms of the person's goal(s). Fear will be provoked when individuals believe that failure is a threat to the achievement of their goal(s). These beliefs (or schemas) and their strength directly influence one's perception of the consequences of failure. The stronger the belief in the aversiveness of the consequences of failure, the greater the FF is likely to be (Conroy et al., 2002). The strength of these beliefs can be related to trait-anxiety. As such, FF can represent a dispositional tendency to experience apprehension and anxiety in evaluative situations because individuals have learned that failure is associated with aversive consequences (Conroy \& Elliot, 2004).

Experiencing fear and anxiety are associated with a shift of one's attention from the task at hand toward threatening environmental stimuli, and there is a subsequent tendency to dwell on these stimuli (delayed disengagement; Derryberry \& Reed, 2002; Fox, Russo, \& Dutton, 2002). When individuals are 
threatened with an aversive event they seek out and monitor information about the threat. There is a general tendency to direct one's attention toward potentially threatening stimuli, which can be further enhanced by high levels of anxiety and/ or fear, especially among those possessing high trait anxiety (Fox et al., 2002; Ohman \& Mineka, 2001). High trait-anxious individuals and individuals who fear the stimuli (e.g., spiders) rapidly detect threat stimuli and can have difficulty disengaging their attention from the threat. Thus, the presence of fear-relevant stimuli in the environment can result in anxiety-related failure to rapidly disengage from threatening stimuli and can result in a decline in task performance. Based on this body of research, it can be proposed that experiencing FF and anxiety precompetition can hinder athletic performance because they direct athletes' attention to external threat stimuli (i.e., failure), to the potential consequences of failure, and to the athlete's own negative internal states (i.e., heightened negative cognition and affect). This can impede athletes' task-relevant attention (i.e., reduce focus and concentration) and, subsequently, can impair the quality of their sport performances. Thus, it can be suggested that FF can indirectly lead to failure. This assumption, however, awaits investigation.

In the current study, some athletes reported that to avoid failure they increased their amount of training and effort and pushed themselves to train harder. They viewed exerting maximum effort as a behavior that serves to reduce FF (Birney et al., 1969). One strategy used in an attempt to avoid failure is to ensure the attainment of a goal, which theoretically can be achieved by improving skill through practice and by investing maximum effort. This, however, does not guarantee that the skill will be improved and goal attainment will become more probable. Furthermore, if nonattainment follows maximum effort, it becomes much more difficult to avoid implications about the athlete's underlying skill and it can place the individual on the line to be evaluated (which can be difficult for someone who fears failure; Birney et al., 1969). Moreover, increased training by athletes can lead to overtraining, a potential source of burnout, and this can consequently lead to athletes' withdrawal from the sport both at junior and senior elite levels (Gould, Udry, Tuffey, \& Loehr, 1996; Smith, 1989). Therefore, although some of the athletes in the current study viewed increased training as a positive outcome of FF, increased training may not be an effective response to FF.

It was inferred from the data that the athletes employed three types of coping strategies, AFC strategies (cognitive and behavioral), EFC strategies, and PFC strategies. All of the athletes employed AFC strategies and EFC strategies, and eight of the nine participants also employed PFC strategies. Thus, the majority of the athletes employed all three strategies in combination. This finding is consistent with that of other sport-related studies (e.g., Gould, Udry, Bridges, \& Beck, 1997; Grove, Eklund, \& Heard, 1997; Grove, Lavallee, \& Gordon, 1997; Poczwardowski \& Conroy, 2002) that have examined athletes' coping behaviors related to a variety of variables (e.g., performance and competition, injuries, retirement from sport, performance slumps, success and failure). These studies have consistently shown that athletes cope differently across a number of situations and employ a variety of PFC, EFC, and AFC strategies in combination. However, these sport-related studies have consistently found that athletes prefer PFC strategies (e.g., planning, task focus, suppression of other activities, instrumental social support) rather than EFC or AFC strategies (e.g., distancing, venting of emotions, 
behavioral or mental disengagement). These findings are in contrast to the findings of the current study, which found that the athletes employed mostly AFC, followed by EFC and PFC strategies. Thus, PFC strategies were least employed by the participating athletes to cope with their fears of failure. This difference in findings may be due to the different contexts investigated in the current study and in the previous sport-related studies and to differences in participants' ages (i.e., adolescents might employ different coping strategies than adults). This difference may also be attributed to methodological differences and to labeling (or coding) differences between researchers in qualitative research. More research is therefore needed to understand this difference.

Although most stressors elicit both PFC and EFC strategies, PFC tends to be mostly employed when individuals feel that something constructive can be done about the stressor, while EFC tends to occur when individuals feel that the stressors are uncontrollable and must be endured. Accordingly, it can be suggested that FF may be a stressor that these athletes perceived to be beyond their control. After all, athletes do not always have complete control over the outcome of their performances or the consequences of their failures. This may explain the slightly greater use of AFC and EFC strategies. Regardless, AFC strategies have been described as "less useful" and "dysfunctional" in most situations (Carver et al., 1989), as they divert one's attention away from addressing the stressor and often lead to negative emotional and motivational outcomes (because AFC strategies indicate loss of situational control; Parker \& Endler, 1996). Again, all of the athletes used EFC strategies, all employed AFC strategies, and eight out of the nine used PFC strategies. As such, it appears that while the participating athletes employed many effective coping strategies, they also all engaged in ineffective coping strategies to deal with their fears of failure.

Coping and emotion regulation are overlapping constructs (Gross, 2002; Gross \& Thompson, 2007). Reappraisal and suppression are self-regulation strategies that aim to decrease negative emotional responses. From this perspective, it can be argued that EFC and AFC strategies were employed by the athletes to regulate their heightened negative emotional responses during the period before competitions. Through reappraisal, the athletes may have sought to change their thinking about failure (e.g., positive reinterpretation, positive self-talk), thus decreasing its emotional impact. Cognitively reevaluating failure (which is potentially a negative emotion-inducing stimulus) may have helped them alter its meaning and thus reduce the level of FF that they experienced. On the other hand, suppression is a self-regulation strategy that encompasses the continual suppression of thoughts that evoke negative emotional responses (Gross \& Thompson, 2007). Indeed, some of the participating athletes reported that they pushed thoughts of failure away (mental disengagement) to help them cope with their FF before competition. In fact, some athletes perceived that thinking about failure actually leads to failure. Researchers have previously referred to this as thoughtaction fusion (Abramowitz, Whiteside, Lynam, \& Kalsy, 2003). Thought-action fusion occurs for an individual when she or he believes that unwanted thoughts about distressing actions are equivalent to the actions themselves, and that thinking about these distressing events makes them more likely to happen in the future. It is one's catastrophic beliefs about the meaning of the consequences of such thoughts that elicit anxiety, and to neutralize the thoughts or to prevent the possi- 
ble occurrence of disastrous consequences, individuals often engage in avoidance behavior (Abramowitz, et al., 2003).

\section{Recommendations for Practice}

It appears from our findings that FF had a short-term impact on the athletes' wellbeing, interpersonal behavior, sport performance, and schoolwork and that the athletes employed both effective and ineffective coping strategies to deal with the effects of FF before competition. These are important preliminary findings, as athletes who engage in ineffective coping skills to deal with their fears of failure may experience poor performance, negative affect, and a desire to withdraw from sport. In contrast, researchers have found that athletes with more personal and environmental resources may employ more PFC and less AFC strategies (Holahan $\&$ Moos, 1990). Therefore, it is important for practitioners to teach young elite athletes to employ effective coping strategies, such as PFC (e.g., seeking instrumental social support, visualization, planning, reframing) to deal with their fears of failure, as these can potentially help them attain a balanced emotional state and a high level of motivation. Such skills may also indirectly impact their sport performance and may assist in social development because they can generalize these coping skills to other areas of their lives (Smith, 1999).

Through cognitive-behavioral techniques, practitioners can teach young elite athletes how to confront their fears; how to put into perspective sporting demands, expectations, and experiences of failure; and how to challenge their perceptions of the meaning of failure in sport (i.e., develop a process orientation rather than an outcome orientation). Common traditional cognitive-behavioral techniques include challenging irrational beliefs, reframing, rehearsing the use of different self-statement, using different self-statements in real situations, scaling feelings (e.g., scaling anxiety level on 0-100 scale), thought stopping, exposure, systematic desensitization, and homework assignments (tasks to practice new behavior and cognitive strategies between therapeutic sessions; e.g., Ellis, 2003; Head \& Gross, 2003; Newman, 2003). Such techniques can also help reduce the strength of athletes' beliefs in the aversive consequences of failure, which provide the basis for FF. Furthermore, practitioners can use these techniques to help enhance the self-perceptions and motivation of young athletes after failure.

Practitioners can also indirectly help young elite athletes develop effective coping strategies to deal with their fears of failure by delivering psychosocial intervention programs to coaches, parents, and others who work closely with the athletes and who play important roles in their lives, their sporting careers, and their social development. Parents and coaches can be educated on how to recognize signs of FF among young athletes and how to apply various techniques (e.g., putting things into perspective, challenging perceptions of failure in sport) to assist the athletes. Both direct and indirect approaches can help young elite athletes develop effective coping responses. We echo Poczwardowski and Conroy's (2002) statement that "excellence in coping precedes excellence in performance" (p. 313), and Lazarus' (2000) advice, "the right kind of coping in an important competition could lead athletes to become re-motivated, and thereby, capable of attending and concentrating effectively to display their typically high standard of excellence" (p. 237). 


\section{Limitations, Future Directions, and Conclusions}

The present study represents one of the few efforts at examining the coping behaviors of young elite athletes with regard to FF. Although a preliminary examination, the current study has yielded informative findings and offers practitioners and theorists insight into FF and the coping responses of young elite athletes. Due to the small number of participants, however, the findings cannot be generalized to the wider population of young elite athletes. Therefore, future research will benefit from a quantitative examination of $\mathrm{FF}$ and associated coping responses among a larger sample size, thereby producing empirical findings that are more generalizeable.

Fear of failure is an important construct to investigate because (a) it allows researchers to explore the development of adaptive and maladaptive behaviors that have social implications, and (b) FF may indirectly contribute to performance decrements and frustration, possibly detracting from the quality of the experience of sport participation (Conroy, 2001). Ignoring FF and the problems associated with FF can potentially have negative consequences for individuals in achievement settings, as individuals may continue to experience distress in such settings, may learn to associate distress with achievement activity, and thus may experience a barrier to their future participation in achievement activities. This may be especially disadvantageous for children because early performance levels often determine later achievement opportunities. Moreover, the negative effects of FF may worsen over time (Conroy, 2001). Researchers are therefore encouraged to continue to explore and classify coping behaviors of young athletes with regard to FF among different age groups. Researchers may also consider examining FF in relation to individual variables (e.g., personality factors such as optimism-pessimism, self-handicapping, perfectionism) and interpersonal variables (e.g., coachathlete, parent-athlete, and peer relationships). Such research will enhance knowledge and help psychologists develop a better conceptual understanding of the FF phenomenon in the sport domain, where research on FF is greatly needed.

Further research will also inform prevention, assessment, diagnosis, and treatment of FF and other performance anxiety issues in sport. By reducing young athletes' FF, practitioners may help enhance their sporting performances, experiences in sport, and overall well-being, and may reduce the negative consequences associated with FF. As such, sport practitioners have an opportunity to contribute not only to young athletes' sport performance, but also to the quality of their lives and their social development.

\section{References}

Abramowitz, J.S., Whiteside, S., Lynam, D., \& Kalsy, S. (2003). Is thought-action fusion specific to obsessive-compulsive disorder?: A mediating role of negative affect. Behaviour Research and Therapy, 41, 1069-1079.

Arskey, H., \& Knight, P. (1999). Interviewing for social sciences. London: Sage. Atkinson, J.W. (1964). An introduction to motivation. Princeton, NJ: Van Nostrand.

Barlow, D.H. (2000). Unraveling the mysteries of anxiety and its disorders from the perspective of emotion theory. The American Psychologist, 55, 1245-1263.

Barlow, D.H. (2002). Anxiety and its disorders: The nature and treatment of anxiety and panic (2nd ed.). New York: Guilford. 
Birney, R.C., Burdick, H., \& Teevan, R.D. (1969). Fear of failure. New York: Van Nostrad.

Bringer, J.D., Johnston, L.H., \& Brackenridge, C.H. (2004). Maximizing transparency in a doctoral thesis: The complexities of writing about the use of QSR* NVIVO within grounded theory study. Qualitative Research, 4, 247 - 265.

Carver, C.S., \& Scheier, M.F. (1998). On the self-regulation of behavior. New York: Cambridge University Press.

Carver, C.S., Scheier, M.F., \& Weintraub, J.K. (1989). Assessing coping strategies: A theoretically based approach. Journal of Personality and Social Psychology, 56, 267283.

Conroy, D.E. (2001). Fear of failure: An exemplar for social development research in sport. Quest, 53, 165-183.

Conroy, D.E., \& Elliot, A.J. (2004). Fear of failure and achievement goals in sport: Addressing the issue of the chicken and the egg. Anxiety, Stress, \&. Coping, 17, 271-286.

Conroy, D.E., Poczwardowski, A., \& Henschen, K.P. (2001). Evaluative criteria and consequences associated with failure and success for elite athletes and performing artists. Journal of Applied Sport Psychology, 13, 300-322.

Conroy, D.E., Willow, J.P., \& Metzler, J.N. (2002). Multidimensional fear of failure measurement: The Performance Failure Appraisal Inventory. Journal of Applied Sport Psychology, 14, 76-90.

Covington, M.V. (1992). Making the grade: A self-worth perspective on motivation and school reform. New York: Cambridge University Press.

Crocker, P.R., \& Graham, T.R. (1995). Coping by competitive athletes with performance stress: Gender differences and relationships with affect. The Sport Psychologist, 9, 325-338.

Crocker, P.E., \& Isaak, K. (1997). Coping during competitions and training sessions: Are youth swimmers consistent? International Journal of Sport Psychology, 28, 355369.

Derryberry, D., \& Reed, M.A. (2002). Anxiety-related attentional biases and their regulation by attentional control. Journal of Abnormal Psychology, 111, 225-236.

Elliot, A.J., \& Church, M.A. (1997). A hierarchical model of approach and avoidance achievement motivation. Journal of Personality and Social Psychology, 72, 218-232.

Elliot, A.J., \& Harackiewicz, J.M. (1996). Approach and avoidance achievement goals and intrinsic motivation: A mediational analysis. Journal of Personality and Social Psychology, 70, 461-475.

Elliot, A.J., \& Sheldon, K.M. (1997). Avoidance achievement motivation: A personal goals analysis. Journal of Personality and Social Psychology, 73, 171-185.

Elliot, A.J., \& McGregor, H. (2001). A $2 \times 2$ achievement goal framework. Journal of Personality and Social Psychology, 80, 501-519.

Ellis, A. (2003). Cognitive restructuring of the disputing of irrational beliefs. In W. O'Donohue, J.F. Fisher, \& S.C. Hays (Eds.), Cognitive behavior therapy: Applying empirically supported techniques in your practice (pp. 79-83). New Jersey: Wiley.

Field, A.P., \& Lawson, J. (2003). Fear information and the development of fears during childhood: Effects on implicit fear responses and behavioural avoidance. Behaviour Research and Therapy, 41, 1277-1293.

Feltz, D.L., \& Albrecht, R.R. (1986). Psychological implications of competitive running. In M.R. Weiss \& D. Gould (Eds.), Sport for children and youths (pp. 225- 230). Champaign, IL: Human Kinetics.

Folkman, S., \& Moskowitz, J.T. (2000). Positive affect and the other side of coping. The American Psychologist, 55, 647-654.

Fox, E., Russo, R., \& Dutton, K. (2002). Attentional bias for threat: Evidence for delayed disengagement from emotional faces. Cognition and Emotion, 16, 355-379. 
Gould, D., Eklund, R.C., \& Jackson, S.A. (1993). Coping strategies used by U.S Olympic wrestlers. Research Quarterly for Exercise and Sport, 64, 83-93.

Gould, D., Horn, T., \& Spreemann, J. (1983). Sources of stress in junior elite wrestlers. Journal of Sport Psychology, 5, 159-171.

Gould, D., Udry, E., Bridges, D., \& Beck, L. (1997). Coping with season-ending injuries. The Sport Psychologist, 11, 379-399.

Gould, D., Udry, E., Tuffey, S., \& Loehr, J. (1996). Burnout in competitive junior tennis players: I. A quantitative psychological assessment. The Sport Psychologist, 10, 322340.

Gray, J.A. (1987). The psychology of fear and stress (2nd ed.). New York: Cambridge University Press.

Gerull, F.C., \& Rapee, R.M. (2002). Mother knows best: Effects of modelling on the acquisition of fear and avoidance behaviour in toddlers. Behaviour Research and Therapy, 40, 279-287.

Gross, J.J. (2001). Emotion regulation in adulthood: Timing is everything. Current Directions in Psychological Science, 10, 214-219.

Gross, J.J. (2002). Emotion regulation: Affective, cognitive and social consequences. Psychophysiology, 39, 281-291.

Gross, J.J., \& Thompson, R.A. (2007). Emotion regulation: Conceptual foundations. In J.J. Gross (Ed.), Handbook of emotion regulation (pp. 3-24). New York: Guilford.

Gullone, E. (1999). The assessment of normal fears in children and adolescents. Clinical Child and Family Psychology Review, 2, 91-106.

Grove, J., Eklund, R.C., \& Heard, N. (1997). Coping with performance slumps: Factor analysis of the Ways of Coping in Sport Scale. Australian Journal of Science and Medicine in Sport, 29, 99-105.

Grove, J., Lavallee, D., \& Gordon, S. (1997). Coping with retirement from sport: The influence of athletic identity. Journal of Applied Sport Psychology, 9, 191-203.

Hayes, S.C., Strosahl, K., Wilson, K.G., Bissett, R.T., \& Pistorello, J. (2004). Measuring experiential avoidance: A preliminary test of a working model. The Psychological Record, 54, 553-578.

Hayes, S.C., Wilson, K.G., Gifford, E.V., Follette, V.M., \& Strosahl, K. (1996). Experiential avoidance and behavioral disorders: A functional dimensional approach to diagnosis and treatment. Journal of Consulting and Clinical Psychology, 64, 1152-1168.

Head, L.S., \& Gross, A.M. (2003). Systematic desensitization. In W. O'Donohue, J.F. Fisher, \& S.C. Hays (Eds.), Cognitive behavior therapy: Applying empirically supported techniques in your practice (pp. 417-422). Hoboken, NJ: Wiley.

Holahan, C.J., \& Moos, R.H. (1990). Life stressors, resistance factors, and improved psychological functioning: An extension of the stress resistance paradigm. Journal of Personality and Social Psychology, 58, 909-917.

Hosek, V., \& Man, F. (1989). Training to reduce anxiety and fear in top athletes. In D. Hackfort \& C.D. Spielberger (Eds.), Anxiety in sport: An international perspective (pp. 247-259). New York: Hemisphere.

Jackson, S.A., Mayocchi, L., \& Dover, J. (1998). Life after winning gold: II. Coping with change as an Olympic gold medalist. The Sport Psychologist, 12, 137-155.

King, E. (1996). The use of the self in qualitative research. In J.T.E. Richardson (Ed.), Handbook of qualitative research methods for psychologists and the social scientists (pp. 175-187). Leicester, UK: British Psychological Society.

King, N.J., Gullone, E., \& Ollendick, T.H. (1998). Etiology of childhood phobias: Current status of Rachman's three pathways theory. Behaviour Research and Therapy, 36, 297-309.

Lawson, J., Banerjee, R., \& Field, A.P. (2007). The effects of verbal information on children's fear beliefs about social situations. Behaviour Research and Therapy, 45, 21-37. 
Lazarus, R.S. (1991). Emotion and adaptation. New York: Oxford University Press.

Lazarus, R.S. (2000). How emotions influence performance in competitive sports. The Sport Psychologist, 14, 229-252.

Lazarus, R.S. (1999). Stress and emotions: A new synthesis. London: Free Association Books.

Madden, C. (1995). Ways of coping. In T. Morris, \& J. Summers (Eds.), Sport psychology: Theory, applications and issues (pp. 288-310). Milton, Qld: John Wiley.

Martens, R., Burton, D., Vealey, R.S., Bump, L.A., \& Smith, D.E. (1990). Development and validation of the Competitive State Anxiety Inventory-2. In R. Martens, R.S. Vealey, \& D. Burton (Eds.), Competitive anxiety in sport (pp. 117-190). Champaign, IL: Human Kinetics.

Martin, A.J., \& Marsh, H.W. (2003). Fear of failure: Friend or foe? Australian Psychologist, 38, 31- 38.

McClelland, D.C. (1958). The importance of early learning in the formation of motives. In J.W. Atkinson (Ed.), Motives in fantasy, action, and society (pp. 437-452). Princeton, NJ: Van Nostrand.

McClelland, D.C., Atkinson, J.W., Clark, R.A., \& Lowell, E.L. (1958). A scoring manual for the achievement motive. In J.W. Atkinson (Ed.), Motives in fantasy, action and society (pp. 179-204). New York: Van Nostrand.

Morris, R.J., \& Kratochwill, T.R. (1998). The practice of child therapy. Boston: Allyn \& Bacon.

Newman, C.F. (2003). Cognitive restructuring: Identifying and modifying maladaptive schemas. In W. O'Donohue, J.F. Fisher, \& S.C. Hays (Eds.), Cognitive behavior therapy: Applying empirically supported techniques in your practice (pp. 89-95). Hoboken, NJ: Wiley.

Ohman, A., \& Mineka, S.M. (2001). Fear, phobias, and preparedness: Toward an evolved module of fear and fear learning. Psychological Review, 108, 483-522.

Parker, J.D., \& Endler, N.S. (1996). Coping and defense: A historical overview. In M. Zeidner \& N.S. Endler (Eds.), Handbook of coping (pp. 3-23). New York: Wiley.

Patton, M.Q. (2002). Qualitative research \& evaluation methods (3rd ed.). Thousand Oaks, CA: Sage.

Poczwardowski, A., \& Conroy, D.E. (2002). Coping responses to failure and success among elite athletes and performing artists. Journal of Applied Sport Psychology, 14, 313-329.

QSR NUD*IST N6 [Computer Software]. (2002). Melbourne: Australia.

Reeve, J. (2001). Understanding motivation and emotion (3rd ed.). Orlando, FL: Harcourt.

Sagar, S.S. (2007). Fear of failure among young elite athletes. Unpublished doctoral dissertation, Loughborough University.

Scanlan, T.K., \& Lewthwaite, R. (1984). Social psychological aspects of competition for male youth sport participants: I. Predictors of cognitive stress. Journal of Sport Psychology, 6, 208-226.

Scanlan, T.K., Stein, G.L., \& Ravizza, K. (1991). An in-depth study of former elite figure skaters: III. Sources of stress. Journal of Sport \& Exercise Psychology, 13, 102-120.

Schaefer, B.A., Watkins, M.W., \& Burnham, J.J. (2003). Empirical fear profiles among American youth. Behaviour Research and Therapy, 41, 1093-1103.

Smith, J.A. (1995). Semi-structured interviewing and qualitative analysis. In J.A. Smith, R. Hare, \& L. Van Langenhove (Eds.), Rethinking methods in psychology. London: Sage.

Smith, R.E. (1989). Athletic stress and burnout: conceptual models and intervention strategies. In D. Hackfort \& C.D. Spielberger (Eds.), Anxiety in sport: An international perspective (pp. 183-201). New York: Hemisphere. 
Smith, R.E. (1999). Generalization effects in coping skills training. Journal of Sport \& Exercise Psychology, 21, 189-204.

Strauss, A., \& Corbin, J. (1990). Basics of qualitative research: Grounded theory procedures and techniques. London: Sage.

Sullivan, C.F. (2003). Gendered cybersupport: A thematic analysis of two online cancer support groups. Journal of Health Psychology, 8, 83-103.

Tesch, R. (1990). Qualitative research analysis types and software tools. New York: Falmer.

Treasure, D.C. (2001). Enhancing young people's motivation in youth sport: An achievement goal approach. In G.C. Roberts (Ed.), Advances in motivation in sport and exercise (pp. 177-198). Champaign, IL: Human Kinetics.

Young, J.E., Klosko, J.S., \& Weishaar, M.E. (2003). Schema therapy: A practitioner's guide. New York: Guilford Press.

\section{Appendix 1}

\section{Effects of Fear of Failure: Higher- and Lower-Order Themes and Subthemes}

\section{Effects on Well-Being}

Emotional state $(n=8)$

- Anxious

-Jittery (A4)

-Not sleep well (A5)

- Anxious $(\mathrm{A} 4,9)$

- Worried (A1, 2, 3, 5)

- Stressed - Stressed (A2, 5)

-Tense (A2)

- Scared (A2)

- Upset (A2)

Low self-perception and motivation $(n=3)$

- Lose self-confidence (A2, 4, 5)

- Lose motivation (A5)

- Have negative outlook (A2, 4)

\section{Effects on Interpersonal Behavior}

Become less sociable and tolerant to people $(n=2)$

- Not nice to other people (A5)

- Snappy and nasty with other people (A9)

- Less capable of dealing with world around me (A5) 
Communicate less with people $(n=4)$

- Becoming quieter (A3, 6, 7, 8)

- Talk less with people (A3, 7)

\section{Effects on Sporting Performance}

Sporting performance $(n=3)$

- Not take risks in a match (A6)

- Play more cautiously (A4)

- Swam slower in competitions (A2)

\section{Effects on Schoolwork}

Neglect schoolwork $(n=2)$

- Not concentrate on schoolwork (A5)

- Not think about schoolwork (A8)

Note. High-order themes are in bold, lower-order themes are indicated with ' $\bullet$ ', and subthemes of lower-order themes are indicated with '-'. The numbers in parentheses refer to the athlete who reported the data $(\mathrm{A} 1=$ triathlon; $\mathrm{A} 2=$ field hockey; A3 = kickboxing; A4 = basketball; A5, 8 = football; A6, 7, 9 = tennis).

\section{Appendix 2}

\section{Coping with Fear of Failure: Higher- and Lower- order Themes and Subthemes}

\section{Avoidance-Focused Coping $(n=9)$}

\section{Cognitive Strategies}

\section{Mental disengagement $(n=9)$}

- Pushing thoughts of failure away

- Push thoughts of failure away $(\mathrm{A} 6,8)$

- Push thoughts of failure away and keep a positive mind (A2, 3, 6, 8)

- Push thoughts of failure away because thinking about failure leads to failure

$(\mathrm{A} 1,3,5,6,7,8)$

- Try not to think about failure $(\mathrm{A} 1,4,6)$

- Not think about failure (A1, 2, 8)

- Not think about the consequences of failure $(1,8)$

- Thought control (A1, 5, 6)

- Think about other things (A8, 9) 
Try not to let FF affect me $(n=2)$

- Try not to let FF affect me (A1)

- Not let FF affect me (A2)

\section{Behavioral Strategies}

Become quiet and seek isolation $(n=4)$

- Become quieter $(\mathrm{A} 3,6,7,8)$

- Stay focused and not talk about other things (A3)

- Go to a quiet place $(\mathrm{A} 3,6)$

Not talk about FF $(n=2)$

- Not discuss FF with coaches (A5, 7)

- Not discuss FF with significant others (A7)

Humor $(n=2)$

- Stick my tongue out and laugh (A1)

- Try to joke (A2)

Chill out $(n=1)$

\section{Emotion-Focused Coping $(n=9)$}

\section{Cognitive Strategies}

Positive self-talk $(\boldsymbol{n}=\mathbf{5})$

- Positive self-talk (A4, 6, 8)

- Self-affirmation (A1, 4, 7)

- Self-pep talk (A8)

Positive reinterpretation $(n=7)$

- Perceiving FF as facilitative

- Perceiving FF as a positive $(\mathrm{A} 1,8)$

- Turning FF into a motivational source $(\mathrm{A} 1,2,4,8)$

- Believing anything after failure is positive (A1)

- Adopting a realistic view about failure

- Failure is just having a bad day $(\mathrm{A} 1,2)$

- Hope (A1)

- There is another chance in the future (A8)

- Failure is part of sport and life (A1, 3, 4, 5, 6)

- Accepting FF $(\mathrm{A} 1,2)$

- You got a job to do and can't get stressed (A1)

- Accept FF and live with it (A2)

- Turning to religion (A2) 
Lowering goals $(n=1)$

- Bring your goals down (A4)

Seek emotional social support $(n=1)$

- Talk to friends and family about FF (A2)

\section{Problem-Focused Coping $(n=7)$}

\section{Behavioral Strategies}

\section{Increase effort to prevent failure $(n=6)$}

- Increase training (A2, 3, 4, 6)

- Preparation more exact (A4)

- Concentrate harder (A4, 9)

- Learn about the opponent (A1)

Confronting your fears $(n=4)$

- Face your fears (A5, 9)

- Disregard your fears $(\mathrm{A} 4,6)$

Note. High-order themes are in bold, lower-order themes are indicated with '•', and subthemes of lower-order themes are indicated with '-'. The numbers in parentheses refer to the athlete who reported the data $(\mathrm{A} 1=$ triathlon; $\mathrm{A} 2=$ field hockey; A3 = kickboxing; A4 = basketball; A5, 8 = football; A6, 7, 9 = tennis). 
Copyright of Journal of Clinical Sport Psychology is the property of Human Kinetics Publishers. Inc. and its content may not be copied or emailed to multiple sites or posted to a listserv without the copyright holder's express written permission. However, users may print, download, or email articles for individual use. 